\title{
Intake of butylated hydroxyanisole and butylated hydroxytoluene and stomach cancer risk: results from analyses in the Netherlands Cohort Study
}

Citation for published version (APA):

Botterweck, A. A. M., Verhagen, H., Goldbohm, R. A., Kleinjans, J. C. S., \& van den Brandt, P. A. (2000). Intake of butylated hydroxyanisole and butylated hydroxytoluene and stomach cancer risk: results from analyses in the Netherlands Cohort Study. Food and Chemical Toxicology, 38, 599-605. https://doi.org/10.1016/S0278-6915(00)00042-9

Document status and date:

Published: 01/01/2000

DOI:

10.1016/S0278-6915(00)00042-9

Document Version:

Publisher's PDF, also known as Version of record

Please check the document version of this publication:

- A submitted manuscript is the version of the article upon submission and before peer-review. There can be important differences between the submitted version and the official published version of record.

People interested in the research are advised to contact the author for the final version of the publication, or visit the DOI to the publisher's website.

- The final author version and the galley proof are versions of the publication after peer review.

- The final published version features the final layout of the paper including the volume, issue and page numbers.

Link to publication

\footnotetext{
General rights rights.

- You may freely distribute the URL identifying the publication in the public portal. please follow below link for the End User Agreement:

www.umlib.nl/taverne-license

Take down policy

If you believe that this document breaches copyright please contact us at:

repository@maastrichtuniversity.nl

providing details and we will investigate your claim.
}

Copyright and moral rights for the publications made accessible in the public portal are retained by the authors and/or other copyright owners and it is a condition of accessing publications that users recognise and abide by the legal requirements associated with these

- Users may download and print one copy of any publication from the public portal for the purpose of private study or research.

- You may not further distribute the material or use it for any profit-making activity or commercial gain

If the publication is distributed under the terms of Article $25 \mathrm{fa}$ of the Dutch Copyright Act, indicated by the "Taverne" license above, 


\title{
Research Section
}

\section{Intake of Butylated Hydroxyanisole and Butylated Hydroxytoluene and Stomach Cancer Risk: Results from Analyses in the Netherlands Cohort Study}

\author{
A.A.M. BOTTERWECK ${ }^{1, *}$, H. VERHAGEN ${ }^{2, \dagger}$, R.A. GOLDBOHM ${ }^{3}$, J. KLEINJANS ${ }^{4}$ \\ and P.A. van den BRANDT ${ }^{1}$ \\ 'Department of Epidemiology, Maastricht University, PO Box 616, 6200 MD Maastricht, \\ The Netherlands and ${ }^{2}$ Food Analysis Department, TNO Voeding, PO Box 360, 3700 AJ Zeist, \\ The Netherlands and ${ }^{3}$ Department of Consumer Research and Epidemiology, TNO Voeding, PO Box 360, \\ 3700 AJ Zeist, The Netherlands and ${ }^{4}$ Department of Health Risk Analysis and Toxicology, PO Box 616, \\ 6200 MD Maastricht University, Maastricht, The Netherlands
}

\section{(Accepted 17 October 1999)}

\begin{abstract}
Both carcinogenic and anticarcinogenic properties have been reported for the synthetic antioxidants butylated hydroxyanisole (BHA) and butylated hydroxytoluene (BHT). The association between dietary intake of BHA and BHT and stomach cancer risk was investigated in the Netherlands Cohort Study (NLCS) that started in 1986 among 120,852 men and women aged 55 to 69 years. A semi-quantitative food frequency questionnaire was used to assess food consumption. Information on BHA or BHT content of cooking fats, oils, mayonnaise and other creamy salad dressings and dried soups was obtained by chemical analysis, a Dutch database of food additives (ALBA) and the Dutch Compendium of Foods and Diet Products. After 6.3 years of follow-up, complete data on BHA and BHT intake of 192 incident stomach cancer cases and 2035 subcohort members were available for case-cohort analysis. Mean intake of BHA or BHT among subcohort members was 105 and $351 \mu \mathrm{g} /$ day, respectively. For consumption of mayonnaise and other creamy salad dressings with BHA or BHT no association with stomach cancer risk was observed. A statistically non-significant decrease in stomach cancer risk was observed with increasing BHA and BHT intake [rate ratio (RR) highest/lowest intake of $\mathrm{BHA}=0.57(95 \%$ confidence interval (CI): $0.25-1.30$ ] and BHT $=0.74$ (95\% CI: 0.38-1.43). In this study, no significant association with stomach cancer risk was found for usual intake of low levels of BHA and BHT. (C) 2000 Elsevier Science Ltd. All rights reserved
\end{abstract}

Keywords: butylated hydroxyanisole; butylated hydroxytoluene; stomach neoplasms; cohort study.

Abbreviations: $\mathrm{ALBA}=$ dutch database of food additives; $\mathrm{BHA}=$ butylated hydroxyanisole; $\mathrm{BHT}=$ butylated hydroxytoluene; $\mathrm{CI}=$ confidence interval; $\mathrm{NLCS}=$ Netherlands Cohort Study; $\mathrm{RR}=$ rate ratio.

\section{INTRODUCTION}

Butylated hydroxyanisole (BHA) and butylated hydroxytoluene (BHT) are synthetic antioxidants which are applied in fat and fatty foods to prevent

\footnotetext{
*Corresponding author. Tel: +31-(0)-43-388-23-33; Fax: +31-(0)-43-388-41-28; e-mail: AAM.Botterweck@Epid. unimaas.NL

†Present address: Unilever Research Vlaardingen, Unilever Health Institute, PO Box 114, 3130 AC Vlaardingen, The Netherlands.
}

oxidative deterioration (Addis, 1986). Moreover, BHA and BHT are synthetic phenolic compounds, which are the two most widely applied synthetic antioxidants that have been used since the 1950s (IARC, 1986a,b). BHA and BHT are present in small amounts in many commercial foods and thus constitute a small fraction of the diet of many people (Hocman, 1988).

BHA and BHT were observed to act as anticarcinogens in various animal models (Hocman, 1988; Wattenberg, 1972, 1986; Wattenberg et al., 1980; Williams, 1986; Williams and Iatropoulos, 1996). On the other hand, results have also been reported for 
the carcinogenicity of BHA and BHT in experimental animals (Hocman, 1988; Ito et al., 1983; Williams, 1986). Originally, BHA appeared to have initiating as well as promoting action (Ito et al., 1986b). Recently, it was established that tumor formation appears to involve only tumor promotion (Williams et al., 1999). The target organ for BHA is the forestomach, an organ only present in rodents, whereas BHT has carcinogenic effects in the liver of rats and mice (Clayson et al., 1993; Papas, 1993; Verhagen et al., 1991). Also, esophagus proliferation stimulating effects of BHA have been reported in non-rodents (pigs, monkeys) in response to BHA administration (Papas, 1993; Verhagen et al., 1991a). In a landmark publication in 1981 it was estimated that food additives accounted for less than $1 \%$ of all cancer deaths. The range of estimates for food additives varied from $+2 \%$ to $-5 \%$, suggesting that food additives may either have a positive or negative contribution to cancer development (Doll and Peto, 1981).

However, the effects of BHA and BHT on humans have been limited. A study by Verhagen et al. revealed no clinical effects (Verhagen et al., 1989a). Because of the widespread use of BHA and BHT in food products and as a consequence long-term and widespread exposure of humans, it is important to investigate the potential health risks associated with their dietary intake. In the Netherlands Cohort Study (NLCS), a prospective cohort study in which various risk factors for stomach cancer have been investigated (Botterweck et al., 1998), we were also able to study the effect of usual BHA and BHT intake on stomach cancer risk.

\section{MATERIALS AND METHODS}

\section{Subjects and study design}

The Netherlands Cohort Study on diet and cancer (NLCS) is a prospective cohort study which started in September 1986 among the general population in The Netherlands (van den Brandt et al., 1990a). The cohort included 62,573 women and 58,279 men aged 55 to $69 \mathrm{yr}$ in 1986. At baseline, the cohort members completed a mailed, self-administered questionnaire on dietary habits, smoking, occupation, medical history, personal and family history of cancer, and demographic data. Follow-up for the incidence of cancer has been established by record linkage with cancer registries and a pathology register (van den Brandt et al., 1990b). For data analysis the casecohort approach was used in which cases are derived from the entire cohort, while the person-years at risk of the entire cohort are estimated from a random sample of 3500 subjects (subcohort) (Self and Prentice, 1988). This subcohort of 1812 women and 1688 men has been followed up biennially for vital status information in order to estimate the accumulated person time in the cohort. No subcohort members were lost to follow-up. The present analysis is restricted to cancer incidence in the first $6.3 \mathrm{yr}$ of follow-up from September 1986 until December 1992. After the exclusion of subjects reporting prevalent stomach cancer at base-line $(n=33)$, cases with in situ stomach carcinoma $(\mathrm{n}=2)$, and cases without microscopically confirmed stomach cancer $(n=2)$, there were 310 incident (242 men, 68 women) stomach carcinoma cases remaining. In the subcohort, 1630 men and 1716 women remained after the exclusion of prevalent cancer cases other than skin cancer.

\section{Exposure assessment}

For assessing BHA and BHT intake, both information on consumption of potential BHA- and/or BHT-containing foods and brand names of these foods were needed. Consumption of potential BHAand/or BHT-containing foods was assessed using the dietary section of the baseline questionnaire of the NLCS. The dietary section was a 150 -item semiquantitative food frequency questionnaire concentrating on usual consumption of food and beverages during the year preceding the start of the study. The questionnaire was validated against a 9day diet record (Goldbohm et al., 1994). Among other questions, participants were asked to report their frequency of consumption of potential BHAand/or BHT-containing foods: cooking fats, oils, dried soups (from a pack), mayonnaise and other creamy salad dressings, potato products, cereals and cereal products, pastry, cakes and biscuits, sugar, sweets and sweet spreads, nuts, seeds and snacks (Verhagen et al., 1990a). They could choose one of six frequency categories, ranging from "never or less than once per month" to "6-7 times per week". Standard portion sizes were used to calculate daily intake. Participants were asked to specify type and brand for cooking fats (for preparing meat, fish and chips), oils, butter, mayonnaise and other creamy salad dressings and dried soups. Only those products with brand names could be used to obtain information on BHA and BHT content.

\section{Collection of information on BHA and BHT content of foods}

Information on BHA and/or BHT content was obtained by chemical analysis of selected potential BHA- and/or BHT- containing foods and by the use of two other information sources: a Dutch database of food additives for people with food intolerance and allergy (ALBA) and the Dutch Compendium of Foods and Diet Products (Compendium of Food and Diet Products, 1989/1990).

\section{Chemical analysis}

The most frequently mentioned brand names of cooking fats, oils, mayonnaise and other creamy salad dressings and dried soups in the baseline questionnaire from a random sample of 400 cohort par- 
ticipants were selected in 1988. Because the fat content of dried soups is very low and as a consequence the BHA and/or BHT content, dried soups were not regarded as relevant for BHA and/or BHT intake. Dried soups were therefore excluded from chemical analysis. Although oils contain naturally occurring tocopherols and do not require the addition of BHA or BHT, a number of oils were still analysed. Finally, in 1990, 55 brand-specific foods (30 mayonnaise and other creamy salad dressings, 11 oils and 14 cooking fats) were bought in local supermarkets and analysed by means of HPLC.

\section{Other data sources}

The ALBA database comprises data on the presence or absence of food additives in food products specified to type and brand for people with food intolerance and allergy. Regarding BHA and BHT, a list of food brand names containing BHA and/or BHT was obtained for the year 1989. Information before 1989 was not available.

The Compendium of Food and Diet Products contains information about the composition of a selection of (diet) foods by type and brand and is used by general practitioners and dieticians (Compendium, 1989/ 1990). Since 1989, information about the presence of food additives in food and diet products was added to the Compendium. Both ALBA and the Compendium obtained their information from food manufacturers. We assumed that the BHA and/or BHT content of foods in 1989/1990 was the same as in 1986 .

Based on the information of these three sources, it could be concluded that in this study only mayonnaise and other creamy salad dressings contained BHA or BHT. There were no foods that contained both BHA and BHT.

\section{Calculation of BHA and BHT intake}

Foods were coded to contain BHA or BHT if at least one of the three sources (chemical analysis, ALBA or Compendium) showed that BHA or BHT was present. If, in addition, the amount of BHA and/ or BHT was known by chemical analysis, this information was also used. Foods for which no information was available were coded as missing. Foods of which the presence of BHA or BHT was demonstrated but no amount of BHA or BHT was known, the average content of BHA or BHT in mayonnaise or other salad dressings from which the BHA or BHT concentration was known, was substituted. Mean daily intake was calculated by multiplying BHA or BHT content of foods (in $\mu \mathrm{g}$ per gram) and consumption of mayonnaise and other creamy salad dressings (in gram per day).

\section{Covariates}

Other factors possibly relevant for the association between BHA and BHT and stomach cancer risk that were measured in the baseline questionnaire included age, sex, level of education (lower, medium and higher vocational school) (van Loon et al., 1998), stomach disorders (yes or no), family history of stomach cancer (yes or no), smoking status (never/ ex/current smoker), fruit and vegetable consumption (in g/day)(Botterweck et al., 1998), monounsaturated fat and polyunsaturated fat consumption (in $\mathrm{g} / \mathrm{day}$ ). In this study, stomach disorders were defined as having any stomach disease in the past which required medical attention (e.g. peptic ulcer, gastritis).

\section{Data analysis}

From an epidemiological point of view it is important to investigate the association between the consumption of mayonnaise and other creamy salad dressings per se and stomach cancer risk. All cases (282) and subcohort members (3123) could be classified as user or non-user of mayonnaise and other creamy salad dressings. Then, the association between the use of mayonnaise and creamy salad dressings with BHA or BHT and intake of BHA or BHT and stomach cancer risk was examined. These analysis were based on 192 cases $(68.1 \%)$ and 2035 subcohort members $(65.2 \%)$ with complete data on BHA or BHT content of mayonnaise and other creamy salad dressings. These subjects were classified by the consumption of BHA- or BHT-containing foods (yes or no) and categorized into three categories of BHA $(0,>0-70,>70 \mu \mathrm{g} /$ day $)$ and BHT $(0$, $>0-225,>225 \mu \mathrm{g} /$ day $)$.

For data analysis, the GLIM statistical package was used (Baker, 1985). Case-cohort analyses were performed based on the assumption that survival times were exponentially distributed in the follow-up period (Self and Prentice, 1988). Specific macros were developed to account for the additional variance introduced by using the subcohort instead of using the entire cohort (Volovics and van den Brandt, 1997). All analyses were conducted for men and women together. Multivariate rate ratios (RRs) of stomach cancer and their $95 \%$ confidence intervals (CI) were computed for all variables. Tests for trend in the RRs were based on likelihood ratio tests. The multivariate model included age, sex, level of education, stomach disorders, family history of stomach cancer and smoking status. Other multivariate models which included also monounsaturated fat or polyunsaturated fat or fruit and vegetable consumption were tested too.

Because of potential influence of preclinical symptoms of stomach cancer on food consumption, all analyses were also conducted after excluding cases diagnosed in the first and second year of follow-up (Botterweck et al., 1998; van den Brandt et al., 1994).

\section{RESULTS}

Table 1 shows the consumption of mayonnaise and creamy salad dressings in cases and subcohort members. Of the subcohort members, $65.8 \%$ consumed mayonnaise and creamy salad dressings. For the sub- 
Table 1. Users of mayonnaise and creamy salad dressings and consumption of mayonnaise and creamy salad dressings with BHA or BHT in stomach cancer cases and subcohort members with complete consumption data: Netherlands Cohort Study 1986-1992

\begin{tabular}{lcc}
\hline & Cases $\mathrm{n}=282$ & Subcohort $\mathrm{n}=3123$ \\
\cline { 2 - 3 } & $\mathrm{n}(\%)$ & $\mathrm{n}(\%)$ \\
\hline $\begin{array}{l}\text { Users of mayonnaise and } \\
\text { creamy salad dressings }\end{array}$ & $180(63.8)$ & $2056(65.8)$ \\
$\begin{array}{l}\text { Non-users } \\
\text { Consumption of mayonnaise }\end{array}$ & $102(36.2)$ & $1067(34.2)$ \\
$\begin{array}{l}\text { and creamy salad dressings: } \\
\text { with BHA }\end{array}$ & $43(15.2)$ & $497(15.9)$ \\
$\quad$ without BHA & $149(52.8)$ & $1538(49.2)$ \\
$\quad$ with BHT & $43(15.2)$ & $499(16.0)$ \\
without BHT & $149(52.8)$ & $1536(49.2)$ \\
\hline
\end{tabular}

*There was no information on BHA and/or BHT content of foods in 90 cases $(31.9 \%)$ and 1088 subcohort members $(34.8 \%)$.

jects with complete data on the consumption of mayonnaise and creamy salad dressings with BHA or BHT, a slightly smaller percentage of cases used foods with BHA or BHT than the subcohort members.

In Table 2, the distribution of BHA or BHT intake in cases and subcohort members is presented. Mean intake of BHA or BHT among subcohort members was 105 and $351 \mu \mathrm{g} / \mathrm{day}$, respectively. Intake of BHA or BHT was lower in cases at 89 and $330 \mu \mathrm{g} /$ day, respectively. There were small differences in distribution of BHA or BHT intake categories between cases and subcohort members. In the highest intake category of the two variables the percentage of cases was slightly lower compared to the subcohort members.

RRs of stomach cancer according to the consumption of mayonnaise and creamy salad dressings, the use of mayonnaise and creamy salad dressings with BHA or BHT and intake of BHA or BHT are shown in Table 3. Multivariate analyses of all stomach cancer cases and multivariate analyses after exclusion of cases diagnosed in the first and second year of follow-up are shown. For consumption of mayonnaise and creamy salad dressings and BHAor BHT-containing foods no association with stomach cancer risk was observed. After exclusion of first and second year cases, the RRs of the consumption of mayonnaise and creamy salad dressings

Table 2. Mean intake of BHA and BHT among users of mayonnaise and creamy salad dressings ( $\mu \mathrm{g} /$ day) and distribution of BHA and BHT intake in stomach cancer cases and subcohort members: Netherlands Cohort Study 1986-1992

\begin{tabular}{lcc}
\hline & Cases & Subcohort \\
\hline Mean intake $( \pm$ SD) in $\mu$ g/day of: & & \\
BHA & $89( \pm 83)$ & $105( \pm 183)$ \\
BHT & $330( \pm 315)$ & $351( \pm 347)$ \\
& & \\
BHA intake $(\mu \mathrm{g} /$ day $)$ & $\mathrm{n}(\%)$ & $\mathrm{n}(\%)$ \\
0 & $161(57.1)$ & $1638(52.4)$ \\
$>0-70$ & $19(6.7)$ & $207(6.6)$ \\
$>70$ & $12(4.3)$ & $190(6.1)$ \\
BHT intake $(\mu \mathrm{g} /$ day $)$ & $161(57.1)$ & $1644(52.6)$ \\
0 & $16(5.7)$ & $182(5.8)$ \\
$>0-225$ & $15(5.3)$ & $209(6.7)$ \\
$>225$ & & \\
\hline
\end{tabular}

and BHT-containing foods did not change. However, the RR of BHA-containing foods decreased to 0.89 (95\% CI $0.58-1.37)$ after exclusion of first and second year cases. A decreasing stomach cancer risk was observed with increasing BHA or BHT intake. The RRs of high intake $v s$ low intake of BHA and BHT were 0.84 (95\% CI 0.45-1.57) and 0.82 (95\% CI 0.46-1.43), respectively. However, the RRs for stomach cancer with each consumption category of the two variables, nor the tests for trend were statistically significant. After exclusion of cases diagnosed in the first or second follow-up year, the RRs of the highest intake of BHA and BHT compared to the lowest intake category decreased to 0.57 (95\% CI $0.25-1.30)$ and 0.74 (95\% CI $0.38-1.43)$, respectively. Again, none of the RRs were statistically significant different from unity and none of the tests for trend were statistically significant.

Inclusion of monounsaturated fat or polyunsaturated fat consumption or fruit and vegetable consumption in the model did not change the risk estimates.

\section{DISCUSSION}

This prospective cohort study is the first epidemiologic study that evaluated the association between dietary intake of BHA and BHT and stomach cancer risk. We found no association between the consumption of foods containing BHA or BHT and stomach cancer risk. There seemed to be an indication for a decreased stomach cancer risk with increasing BHA and BHT intake.

\section{Methodological considerations}

The cohort study has been performed in a large sample of the general population aged 55-69 yr at baseline. After $6.3 \mathrm{yr}$ of follow-up, 192 cases with complete dietary data on BHA or BHT were available for analysis. One of the strengths of this study is that the food consumption was measured before stomach cancer was diagnosed, thus avoiding the problem of biased recall of dietary habits. The follow-up of person-years was $100 \%$ complete and the completeness of cancer follow-up was also very high, indicating that selection bias due to loss of follow-up is unlikely. In multivariate analysis, adjustment was made for all measured variables that were associated with stomach cancer risk in this study. However, residual confounding is possible because some unidentified risk factors may be involved in the relation between BHA or BHT and stomach cancer risk. Because people with preclinical symptoms of stomach cancer are likely to change their dietary habits months or years before stomach cancer is diagnosed, all analyses were performed with and without cases diagnosed in the first and second follow-up year (Botterweck et al., 1998; van den Brandt et al., 1994). In this study, these analyses revealed slightly different RRs. 
Table 3. Rate ratios (RR) and $95 \%$ confidence interval $(95 \% \mathrm{CI})$ of stomach cancer according to use of mayonnaise and creamy salad dressings, consumption of BHA or BHT containing foods and intake of BHA or BHT ( $\mu \mathrm{g} /$ day): Netherlands Cohort Study $1986-1992$

\begin{tabular}{|c|c|c|c|c|}
\hline & $\mathrm{RR}(95 \% \mathrm{CI})^{*}$ & P-trend & $\mathrm{RR}(95 \% \mathrm{CI})^{* *}$ & P-trend \\
\hline \multicolumn{5}{|c|}{ Use of mayonnaise and creamy salad dressings } \\
\hline No & $1.00^{\dagger}$ & & $1.00^{\dagger}$ & \\
\hline Yes & $0.97(0.74-1.26)$ & - & $0.93(0.70-1.25)$ & - \\
\hline \multicolumn{5}{|c|}{ Use of mayonnaise and creamy salad dressings: } \\
\hline without BHA & $1.00^{\dagger}$ & & $1.00^{\dagger}$ & \\
\hline with BHA & $0.97(0.67-1.40)$ & - & $0.89(0.58-1.37)$ & - \\
\hline without BHT & $1.00^{\dagger}$ & & $1.00^{\dagger}$ & \\
\hline with BHT & $0.94(0.65-1.37)$ & - & $0.98(0.65-1.49)$ & - \\
\hline \multicolumn{5}{|c|}{ BHA intake ( $\mu \mathrm{g} /$ day $)$} \\
\hline 0 & $1.00^{\dagger}$ & & $1.00^{\dagger}$ & \\
\hline$>0-70$ & $0.96(0.57-1.61)$ & & $0.80(0.43-1.48)$ & \\
\hline$>70$ & $0.84(0.45-1.57)$ & 0.57 & $0.57(0.25-1.30)$ & 0.12 \\
\hline \multicolumn{5}{|c|}{ BHT intake $(\mu \mathrm{g} /$ day $)$} \\
\hline 0 & $1.00^{\dagger}$ & & $1.00^{\dagger}$ & \\
\hline$>0-225$ & $1.00(0.58-1.76)$ & & $0.85(0.44-1.66)$ & \\
\hline$>255$ & $0.82(0.46-1.43)$ & 0.50 & $0.74(0.38-1.43)$ & 0.30 \\
\hline
\end{tabular}

*Adjusted for age, sex, smoking status, level of education, stomach disorders and stomach cancer in the family.

**Analyses with first and second year cases excluded and adjusted for age, sex, smoking status, level of education, stomach disorders and stomach cancer in the family.

Reference category.

A fact that could have influenced the results is misclassification of exposure. The dietary questionnaire has been designed to assess an individual's long-term food consumption and not specifically to assess the intake of BHA and BHT. Nevertheless, we did have brand specific information of cooking fats, oils, dried soups and mayonnaise and other creamy salad dressings which were potential sources of BHA and BHT. We did not have information on BHA or BHT content of all foods with brand names. In the baseline questionnaire, people reported unknown or foreign brand names. The chemical analysis on BHA and BHT content were performed in a selection of foods. These were the most frequently consumed foods reported by a sample of 400 people from the cohort. Although this was a large sample we could not exclude that rather frequently consumed food products were not mentioned. Both the ALBA database and The Compendium of Food and Diet Products obtained their information from food manufacturers, but not all food manufacturers provided information on food additives. Thus, we did not have $100 \%$ complete data on BHA or BHT content of foods. Despite that, we still could classify nearly $70 \%$ of cases and subcohort members as to whether or not they used BHA- or BHT-containing foods. Furthermore, there is no reason to think that the proportion of stomach cancer cases is different in the group with and without missing data, because information on food consumption was gathered before stomach cancer was diagnosed. However, if misclassification has occurred, this is to be expected non-differential and risk estimates are most likely biased towards the null value.

\section{Interpretation of findings}

In this study, the intake of BHA was 105 (range 23220) $\mu \mathrm{g} /$ day and BHT was 351 (range 19-2052) $\mu \mathrm{g} /$ day which is (approx. 10 times) lower than the intakes estimated in other studies (Kirkpatrick and
Lauer, 1986; Van Dokkum et al., 1982; Verhagen et al., 1990a). In our study, intake values are only based on the consumption of mayonnaise and other creamy salad dressings. In a Dutch market-basket study, BHA and BHT content was obtained by chemical analyses in samples of five out of 12 food groups representing the basic 2-wk diet of 16-18-yr-old male adolescents. The maximal BHA intake (BHT could not be detected) in this Dutch market-basket study was $4 \mathrm{mg} /$ person/day (Van Dokkum et al., 1982). In another Dutch study, the mean daily BHA and/or BHT intake was $4.51 \mathrm{mg}$ or $0.075 \mathrm{mg} / \mathrm{kg} / \mathrm{day}$ for a $60-\mathrm{kg}$ individual. The daily dietary intake of BHA and/or BHT in this study was estimated using data obtained from a nationwide dietary record survey carried out in 1987/1988. The estimates were based on the fat content of seven out of 23 selected food categories and their respective maximum permitted levels of BHA and/or BHT (Verhagen et al., 1990a). The dietary intake of BHA in Canada was estimated using dietary recall data on food consumption and maximum permitted use levels for this antioxidant. The BHA intake ranged from 5.5 to $12.1 \mathrm{mg} /$ person/ day or 0.13 to $0.39 \mathrm{mg} / \mathrm{kg}$ body weight/day (Kirkpatrick and Lauer, 1986). In the latter studies, daily intake of BHA and BHT are probably overestimated. The estimates are based on maximum permitted levels of BHA and/or BHT. These estimates did not account for losses during storage and food processing, or for lower levels of BHA or BHT in foods, because of limited use of BHA or BHT in foods by the manufacturer, or even for the use of other antioxidants in combination with BHA or BHT.

In a limited experiment, the daily individual dietary intake of BHA was assessed using a biological monitoring approach which is based on the fact that $39 \%$ of a single oral dose of BHA is recovered from the urine as phase II conjugates of BHA with glucuronic acid and sulfate (Verhagen et al., 1989b). Six 
volunteers consumed foods that might contain BHA and subsequently collected their urine for $24 \mathrm{hr}$. Another 22 volunteers collected their urine for a 24-hr period without having consumed specific foods. Results of this experiment showed that the actual intake of BHA ranged from less than $1 \mu \mathrm{g}$ to $21.5 \mu \mathrm{g}$ / $\mathrm{kg}$ body weight (Verhagen and Kleinjans, 1991).

Finding no association between BHA and BHT intake and stomach cancer risk incidence substantiates the hypothesis that low intake levels of BHA and BHT are not carcinogenic in humans. To our knowledge, no other relevant data on the evaluation of carcinogenic risk in humans are available. Therefore, the current study findings can only be compared with findings of experimental studies in animals on BHA and BHT. Data from animal experimental studies reported both carcinogenic and anticarcinogenic effects for both BHA and BHT (IARC, 1986a,b; Ito et al., 1986b; Wattenberg, 1985; Wattenberg et al., 1980; Williams et al., 1999). BHA administered in the diet of rats, mice and hamsters induced dose-dependently benign and malignant tumours of the forestomach (Clayson et al., 1993; Ito et al., 1983, 1986a; Masui et al., 1986; IARC, 1986a; Williams, 1986). Not only the forestomach but also other organs of the digestive tract (oesophagus, small intestine and colon/rectum) seem to be potential target tissues for the carcinogenic action of BHA (Verhagen et al., 1990b). When BHT was administered in the diet of mice and rats lung and liver tumours were induced, but there were also studies that reported no increase in tumour incidence were reported (IARC, 1986b). When administered with known mutagens or carcinogens, BHA and BHT either enhanced, inhibited or had no effect on carcinogenity (Hocman, 1988; IARC, 1986a,b; Wattenberg, 1985, 1986; Wattenberg et al., 1980; Williams, 1986). However, for both BHA and BHT anticarcinogenic effects were seen at low doses when given prior to and during exposure to carcinogens (Williams and Iatropoulos, 1996; Williams et al., 1999). The International Agency for Research on Cancer (IARC) that evaluated BHA and BHT, concluded that there is sufficient evidence for carcinogenity of BHA in experimental animals (IARC, 1986a), but for BHT there is limited evidence (IARC, 1986b). Results of experiments performed on animals are difficult to compare with human data and should be interpreted with caution. The amounts of BHA or BHT used in the diet of animals is much higher than the levels permitted in the human diet. Humans are exposed to low concentrations throughout life. Furthermore, humans do not posses a forestomach, and there are metabolic differences between humans and animals.

The finding of an apparent decreased risk with increasing BHA or BHT intake seem to be more in line with the hypothesis that synthetic antioxidants may be protective for cancer and supports findings of studies suggesting that low doses of BHA and BHT inhibit carcinogenesis (Hocman, 1988; Wattenberg,
1986; Williams, 1986; Williams et al., 1999). Antioxidants such as BHA and BHT may have beneficial effects by protecting against toxic compounds that are derived from the destruction of nutrients and the oxidation of fatty acids in foods (Grice et al., 1986).

In conclusion, we found no clear evidence of an association between usual dietary intake of low levels of BHA and BHT and the risk of stomach cancer in humans.

Acknowledgements - We gratefully acknowledge the regional cancer registries, the Dutch national database of Pathology (PALGA), and the National Health Care Information Center for providing incidence data; A. Volovics for statistical advice; E. Dorant, S. Van de Crommert, H. Brants, W. Van Dijk, P. Florax, M. Moll, J. Nelissen, A. Pisters and C. de Zwart for assistance; H. van Monfort, R. Schmeitz, T. van Monfort, and M. de Leeuw for programming and statistical assistance. The Netherlands Cohort Study was supported by the Dutch Cancer Society.

\section{REFERENCES}

Addis P. B. (1986) Occurrence of lipid oxidation products in foods. Food and Chemical Toxicology 24, 1021-1030.

Baker R. (1985) Glim 3.77 Reference manual. Numerical Algorithms Group, Oxford.

Botterweck A. A. M., van den Brandt P. A. and Goldbohm R. A. (1998) A prospective cohort study on vegetable and fruit consumption and stomach cancer risk in the Netherlands. American Journal of Epidemiology 148, 842-853.

Clayson D. B., Iverson F., Nera E. A. and Lok E. (1993) The importance of cellular proliferation induced by BHA and BHT. Toxicology and Industrial Health 9, 231-242.

Compendium of Food and Diet Products (1989/1990) De Toorts, Haarlem.

Doll R. and Peto R. (1981) The causes of cancer: quantitative estimates of avoidable risks of cancer in the United States today. Journal of the National Cancer Institute 66, 1191-1308.

Goldbohm R. A., van den Brandt P. A., Brants H. A., van't Veer P., Al M., Sturmans F. and Hermus R. J. (1994) Validation of a dietary questionnaire used in a large-scale prospective cohort study on diet and cancer. European Journal of Clinical Nutrition 48, 253-265.

Grice H. C., Clayson D. B., Flamm W. G., Ito N., Kroes R., Newberne P. M. and Scheuplein R. (1986) Panel discussion: Possible mechanisms of BHA carcinogenicity from a consideration of its chemical and biological properties. Food and Chemical Toxicology 24, 1235-1242.

Hocman G. (1988) Chemoprevention of cancer: phenolic antioxidants (BHT, BHA). International Journal of Biochemistry and Cell Biology 20, 639-651.

IARC (1986a) IARC Monographs on the Evaluation of Carcinogenic Risk to Humans. Vol. 40. Some Naturally Occurring and Synthetic Food Components, Furocoumarins and Ultraviolet Radiation. Butylated hydroxyanisole (BHA), pp. 123-159. International Agency for Research on Cancer, Lyon.

IARC (1986b) IARC Monographs on the Evaluation of Carcinogenic Risk to Humans. Vol. 40. Some Naturally Occurring and Synthetic Food Components, Furocoumarins and Ultraviolet Radiation. Butylated hydroxytoluene (BHT), pp. 161-206. International Agency for Research on Cancer, Lyon. 
Ito N., Fukushima S., Hagiwara A., Shibata M. and Ogiso T. (1983) Carcinogenicity of butylated hydroxyanisole in F344 rats. Journal of the National Cancer Institute 70, 343-352.

Ito N., Fukushima S., Tamano S., Hirose M. and Hagiwara A. (1986a) Dose response in butylated hydroxyanisole induction of forestomach carcinogenesis in F344 rats. Journal of the National Cancer Institute 77, 1261-1265.

Ito N., Hirose M., Fukushima S., Tsuda H., Shirai T. and Tatematsu M. (1986b) Studies on antioxidants: their carcinogenic and modifying effects on chemical carcinogenesis. Food and Chemical Toxicology 24, 1071-1082.

Kirkpatrick D. C. and Lauer B. H. (1986) Intake of phenolic antioxidants from foods in Canada. Food and Chemical Toxicology 24, 1035-1037.

Masui T., Hirose M., Imaida K., Fukushima S., Tamano S and Ito N. (1986) Sequential changes of the forestomach of F344 rats, Syrian golden hamsters, and B6C3F1 mice treated with butylated hydroxyanisole. Japanese Journal of Cancer Research 77, 1083-1090.

Papas A. M. (1993) Oil-soluble antioxidants in foods. Toxicology and Industrial Health 9, 123-149.

Self S. G. and Prentice R. L. (1988) Asymptotic distribution theory and efficiency results for case-cohort studies. Annals of Statistics 16, 64-81.

van den Brandt P. A., Goldbohm R. A., van't Veer P., Bode P., Dorant E., Hermus R. J. and Sturmans F. (1994) Toenail selenium levels and the risk of breast cancer. American Journal of Epidemiology 140, 20-26.

van den Brandt P. A., Goldbohm R. A., vant Veer P., Volovics A., Hermus R. J. and Sturmans F. (1990a) A large-scale prospective cohort study on diet and cancer in The Netherlands. Journal of Clinical Epidemiology 43, 285-295.

van den Brandt P. A., Schouten L. J., Goldbohm R. A., Dorant E. and Hunen P. M. (1990b) Development of a record linkage protocol for use in the Dutch Cancer Registry for Epidemiological Research. International Journal of Epidemiology 19, 553-558.

Van Dokkum W., De Vos R. H., Cloughley F. A., Hulshof K. F., Dukel F. and Wijsman J. A. (1982) Food additives and food components in total diets in the Netherlands. British Journal of Nutrition 48, 223-231.

van Loon A. J. M., Goldbohm R. A. and van den Brandt P. A. (1998) Socioeconomic status and stomach cancer incidence in men: results from the Netherlands Cohort Study. Journal of Epidemiology and Community Health 52, 166-171.

Verhagen H., Deerenberg I., Marx A., ten Hoor F., Henderson P. T. and Kleinjans J. C. (1990a) Estimate of the maximal daily dietary intake of butylated hydroxyanisole and butylated hydroxytoluene in The Netherlands. Food and Chemical Toxicology 28, 215-220.

Verhagen H., Furnee C., Schutte B., Bosman F. T., Blijham G. H., Henderson P. T., ten Hoor F. and Kleinjans J. C. (1990b) Dose-dependent effects of short-term dietary administration of the food additive butylated hydroxyanisole on cell kinetic parameters in rat gastro-intestinal tract. Carcinogenesis 11, 1461-1468.

Verhagen H. and Kleinjans J. C. S. (1991) Some comments on the dietary intake of butylated hydroxytoluene. Food and Chemical Toxicology 29, 74-75.

Verhagen H., Maas L. M., Beckers R. H., Thijssen H. H., ten Hoor F., Henderson P. T. and Kleinjans J. C. (1989a) Effect of subacute oral intake of the food antioxidant butylated hydroxyanisole on clinical parameters and phase-I and -II biotransformation capacity in man. Human Toxicology 8, 451-459.

Verhagen H., Schilderman P. A. and Kleinjans J. C. (1991) Butylated hydroxyanisole in perspective. Chemico-Biological Interactions 80, 109-134.

Verhagen H., Thijssen H. H., ten Hoor F. and Kleinjans J. C. (1989b) Disposition of single oral doses of butylated hydroxyanisole in man and rat. Food and Chemical Toxicology 27, 151-158.

Volovics A. and van den Brandt P. A. (1997) Methods for the analyses of case-cohort studies. Biometrical Journal 39, 195-214.

Wattenberg L. W. (1972) Inhibition of carcinogenic and toxic effects of polycyclic hydrocarbons by phenolic antioxidants and ethoxyquin. Journal of the National Cancer Institute 48, 1425-1430.

Wattenberg L. W. (1985) Chemoprevention of cancer. Cancer Research 45, 1-8.

Wattenberg L. W. (1986) Protective effects of 2(3)-tertbutyl-4-hydroxyanisole on chemical carcinogenesis. Food and Chemical Toxicology 24, 1099-1102.

Wattenberg L. W., Coccia J. B. and Lam L. K. (1980) Inhibitory effects of phenolic compounds on benzo(a)pyreneinduced neoplasia. Cancer Research 40, 2820-2823.

Williams G. M. (1986) Epigenetic promoting effects of butylated hyroxyanisole. Food and Chemical Toxicology 24, 1163-1166.

Williams G. M. and Iatropoulos M. J. (1996) Inhibition of the hepatocarcinogenicity of aflatoxin B1 in rats by low levels of the phenolic antioxidants butylated hydroxyanisole and butylated hydroxytoluene. Cancer Letters 104, 49-53.

Williams G. M., Iatropoulos M. J. and Whysner J. (1999) Safety assessment of butylated hydroxyanisole and butylated hydroxytoluene as antioxidant food additives. Food and Chemical Toxicology 37, 1027-1938. 